\title{
Eesti ja kujutlus Eestist Skandinaavia saagades
}

Tõnno Jonuks

Eesti ja Skandinaavia asukate meresõidud üle Läänemere algasid juba tuhandeid aastaid tagasi. On ju nooremat pronksiaega, mil levisid suuresti Põhjala kultuuriruumist mõjutatud maapealsed kalmevormid Eestis ja arheoloogilisse materjali hakkas ilmuma arvukamalt skandinaaviapäraseid esemeid, nimetatud vanemaks viikingiajaks. Omalaadne kulminatsioon Läänemere meresõidus saabus Skandinaavia viikingiajaga 8.-11. sajandil, millele järgnes 11.-12. sajandil idateelaste ehk austrvegsmennirite aeg.

Käesolevas artiklis on võetud vaatluse alla 13.-14. sajandil Islandil üles kirjutatud saagad ja püütud seal leiduvate kirjelduste järgi analüüsida põhjalaste, eriti aga Islandi saagakirjanike ettekujutusi paganlikust idast. Saagade valikul on püütud anda ülevaade enamikust Eestit puudutavatest tekstidest, ehkki mõiste Idatee/ Austrvegr puhul võib see olla üsna komplitseeritud. Sel juhul on valitud tekstid, mille puhul saab kontekstist järeldada, et tegevus on toimunud uurimispiirkonnaks valitud Läänemere idarannikul. Idatee all on üldisemalt mõeldud piirkonda Läänemere idarannikust kuni Konstantinoopoli ja Kaspia mereni. Skandinaavia viikingiajal oli see oluline kaubatee, kus liikusid ja kaubitsesid eelkõige Rootsi päritolu kaupmehed ja meresõitjad. Käesolevas artiklis vaadeldakse eelkõige Idatee Eesti- ja Kuramaaga seotud lõiku, seega Idatee alasid, mis saagade kirjapaneku ajaks ei olnud veel kristianiseeritud või olid alles värskelt ristitud. Venemaa (Garðaríkið) ja Novgorod (Hólmgarð) kui kristlikud maad, pealegi veel saagade järgi põhjalastega väga tihedates kontaktides olevad alad ning neist Idateed mööda kaugemale jäävad kristlikud ja mittekristlikud alad jäävad vaatluse alt välja.

Erinevatel põhjustel jääb vaatluse alt kõrvale ka Soome koos selle põhja- ja idapoolsete aladega. Esiteks on toponüüm Finnland ise üsna ebatäpne. On arvatud, et sõna finn on algselt tähistanud laplast ja laienenud sealt soomlastele (Page 1964: 215). Laplaste ja skandinaavlaste eripäraselt tihedasti läbi põimunud kultuur on täheldatav ka laiemalt. Nii on skandinaavia üks salajasemaid 
nõiakunste - seiðr - oletatud lapi laenuks (Strömbäk 1935; EllisDavidson 1976: 290). Viimased uurimused peavad seda pigem ühtseks süsteemiks, mitte aga laenuks (Price 2002: 278). Ka sõna finn rahva nimena tundub märkivat eelkõige laplasi (ja ehk alles sealt on tekkinud seos soomlase ja maagia vahel). Kõige eelneva tõttu pole alati kindel, keda saagas finni all mõeldakse. Lisaks toponüümikale seob finni laplasega ka sõna tähendus liitsõnades (Zilmer 2003). Seega on Soome probleem saagades komplitseeritum ja vajaks iseseisvat uurimust, mis ei ole aga käesoleva artikli eesmärk.

Käesolevas artiklis püüan vaadelda saagasid nende kirjapanijate pilgu läbi, püüdes eriliselt rõhutada seda, mis tavaliselt on jäänud või jäetakse tähelepanu alt kõrvale - üleloomulikke olendeid.

\section{Historiograafiast}

Saagade uurimine ja sidumine Eestiga sai alguse juba 19. sajandi I poolel seoses baltisaksa uurijate tegevusega. Nende põhieesmärgiks oligi siduda saagade andmestik Eesti ja sealtkaudu kogu Põhja-Euroopa ajalooga. Ühena esimestest võiks nimetada Friedrich Kruset (Kruse 1846) ja Johannes van der Smissenit (Smissen 1849). Eesti Vabariigi ajal uurimine laienes ja ilmusid esimesed eestikeelsed saagade ümberjutustused (Kann 1919; Grünfeldt 1922). Tulemusrikkaima uurimusena ilmus Birger Nermani Die Verbindung zwischen Skandinavien und dem Ostbaltikum in der jüngeren Eisenzeit (Nerman 1929).

Nõukogude skandinavistika meelisvaldkonnaks olid varjaagid - teema, mida eesti autorid on vaadelnud vaid põgusalt. Eesti ajalookäsitlustes ongi saagasid kasutatud pigem illustreeriva materjalina esiajaloo lõpu ja keskaja alguse juures. Nõukogude perioodi jäävad aga mitmed skandinavistika uurimisele alustpanevad tõlked. Nii tulekski mainida Rein Sepa tõlkeid Põhjala poeesiast (Sepp 1970; 1990), aga ka Arvo Alase Grettir Asmundripoja ehk Grettir Tugeva (Alas 1982) eestindust. Saaga ja eepika tõlgete kõrval on ilmunud samuti rida populaarteaduslikke tõlkeid Põhjala kultuurist (Steblin-Kamenski 1974; Gurevitš 1975).

Mööda ei saa vaadata ka eesti uurijate tegevusest eksiilis, kus ilmus artikleid eesti ja keskaegse Euroopa kirjanduse seostest, seda eriti Paul Johansenilt (Johansen 1974).

1990. aastatel on Eesti "saaganduses" alanud uus periood. On ilmunud rida tõlkeid mitte ainult saagadest (Alas 2001; 2003), vaid 


\section{Tõnno Jonuks}

ka keskaegsetest kroonikatest (Saluäär 2000), mis loovad vajaliku taustsüsteemi. Ilmunud ja ilmumas on uusi käsitlusi ning artikleid eesti autorite sulest nii saagade ja Eesti seoste kui laiematelgi teemadel (nt Zilmer 2003).

\section{Saagad kui ajalooallikad}

Enamik saagadest on üles kirjutatud 13. ja järgnevatel sajanditel Islandi kloostrites, peamiselt kahes sealses suures keskuses: Pingeyraris ja Hólaris Põhja-Islandil ning preestrite Ari ja Sæmundari tegevuspaigas Skálholtis Lõuna-Islandil. Saagade kirjutusstiil on lähedane ajaloolisele romaanile ja kuna alati ei saa kindel olla nende faktoloogia õigsuses, ongi nad põhiallikaks peamiselt folkloori, mentaliteedi, usundi jmt uurimisel. Samas ei tohi unustada ka saagade ajalooallikalist väärtust.

Vaadeldes saagat kui ajalooallikat tuleb kindlasti tähelepanu juhtida saagakirjanike arusaamadele sündmusest, mida tasus kirja panna. Need olid sellised, mis raputasid tolleaegset ühiskonda, seega sõda, tapmine ja kättemaks, mõnikord ka kauba- või sõjaretkede lühikesed kirjeldused. Selline lähenemine oli iseloomulik keskaja kroonikutelegi. Rahulikku ja igapäevast elu, kus midagi olulist ei juhtunud, ei hakatudki kirjeldama. Seetõttu on saagade maail karm ja verine. Sõja ja röövretkede kirjelduste juures mainitakse küll ka kaubaretki, kuid kuna nende käigus midagi erilist ei juhtunud, ei olnud nende kirjeldused kuigi värvikad. Sellise tendentsi mõistmine sunnib vaatama saagatülisid uue pilguga ja otsima nende vahelt märke, mis kajastaksid kas igapäevast elu või saagajuhtumiste taga olevat ajaloolist sündmust (vt lähemalt Jonuks 2000).

Iseloomustamaks üldiselt Idateega seotud saagateateid, torkab silma, et valdav enamik neist on seotud sõjakäikudega. Tihti on tuldud üle Läänemere ja sõditud siin, teinekord peatudes pikematki aega. Näiteks Egilli saaga 46. peatükk kirjeldab, kuidas Egill sõdis koos sõpradega Austrvegril, jäi siis Kuramaale pidama, tegi kohalikega rahu ja kui rahu läbi sai, sõditi ja rööviti edasi. Teiseks on siinseid maid mainitud pikemate rännakute kontekstis. Kohati kumavad aga tekstidest läbi teated nii kaubitsemisest kui ka muudest suhetest. Eriti põnevad on siinjuures kirjeldused Austrvegril elanud hiiglastest ja teistest üleloomulikest olevustest, kellele pööran järgnevalt põhitähelepanu. 
Tõnno Jonuks

\section{Isiku- ja kohanimedest}

Nagu juba öeldud, on enamik Baltimaadega seotud saagateateist seotud lahingute ja röövretkedega. Võrreldes nüüd neid kirjeldusi teiste saagalahingute või retkedega, on ilmne, et need on üsna sarnased. On lahinguid, kus põhiliste osalejate nimed - Põhjala lahingute kirjelduste tavaline võte - on teada. Tõsi, nende nimede puhul tekib kahtlus, kas tegemist on ikka kohalikke sõdalaste nimedega.

Njálli saagas (Alas 2001) on kirjeldatud mereretkel olevaid Islandi viikingeid. Retke käigus sattusid nad kõigepealt Rafalasse, kus pidasid lahingu, ja seejärel Saaremaale (Eysyslasse), kus kohtasid Taani päritolu orja Tofit. See juhatas neile kätte kahe suure juhi Hallgrimi ja Kollskeggi laagri, järgnes lahing. Enne lahingut on kirjeldatud relvi ja Hallgrimil öeldi olevat atgeir. Eesti keelde on relv tõlgitud taprina (Alas 2001: 61), inglise keelde ka hellebardina (Shetelig 1937: 389) ning arvatakse, et termin on tähistanud kaht odatüüpi: nii kerget viskeoda kui rasket raieoda - hellebardi, mis on olnud mõõga ja oda kombinatsioon (Shetelig 1937: 389). Seepärast oli Gunnarril ka võimalus Hallgrim tappa, torgates tapriteraviku tema kehast läbi (Alas 2001: 62)). Üksikuid selliseid relvi on teada arheoloogilistest leidudest Islandilt (Eldjarn 1956: 282).

Selle loo tõlgendamisel on kaks võimalust: esiteks, Saaremaa viikingitele on omistatud tüüpilised skandinaavlaste nimed ja atgeiri kasutamist, mis võib viidata, et tegemist ei olnudki saarlaste, vaid Saaremaale laagri rajanud Skandinaavia viikingitega (vt Alas 1999: 247). Teise võimalusena võib kaaluda, kas pole tegemist tõenäoliselt ajaloolise sündmuse alusel saaga üleskirjutamise ajal täiendatud looga, kus nimede ja väiksemate detailide lisamise või rekonstrueerimisega on püütud jutustus usutavamaks muuta.

Teine ja vast kuulsaim saagakirjeldus, kus on mainitud nn eestlaste nimesid, on pärit Olaf Tryggvepoja saagast (Óláfs saga Tryggvassonar), mille 6. peatükis kirjeldatakse, kuidas nooruke Olaf langeb koos ema Astridiga Eesti mereröövlite kätte vangi. Eesti "orjakaupmeeste" (Klerkon ja Klerkr) ning maarahva (Réas, Rékon ja Rékoni) nimede kohta on Raivo Palmaru oletanud, et tegemist võis olla hoopis balti nimedega (Palmaru 1980: 269). Samas tuleb märkida, et nii saagakangelaste kui ka saagade kirjapanijate silmis oli siiski selge vahe Baltimaade põhja- ja lõunaosa ning sealsete erinevate keelte vahel, seega ei ole eriti tõenäoline, et need oleks segi aetud, kui lisati juurde kinnitus, et tegemist on eestlastega (Pat 


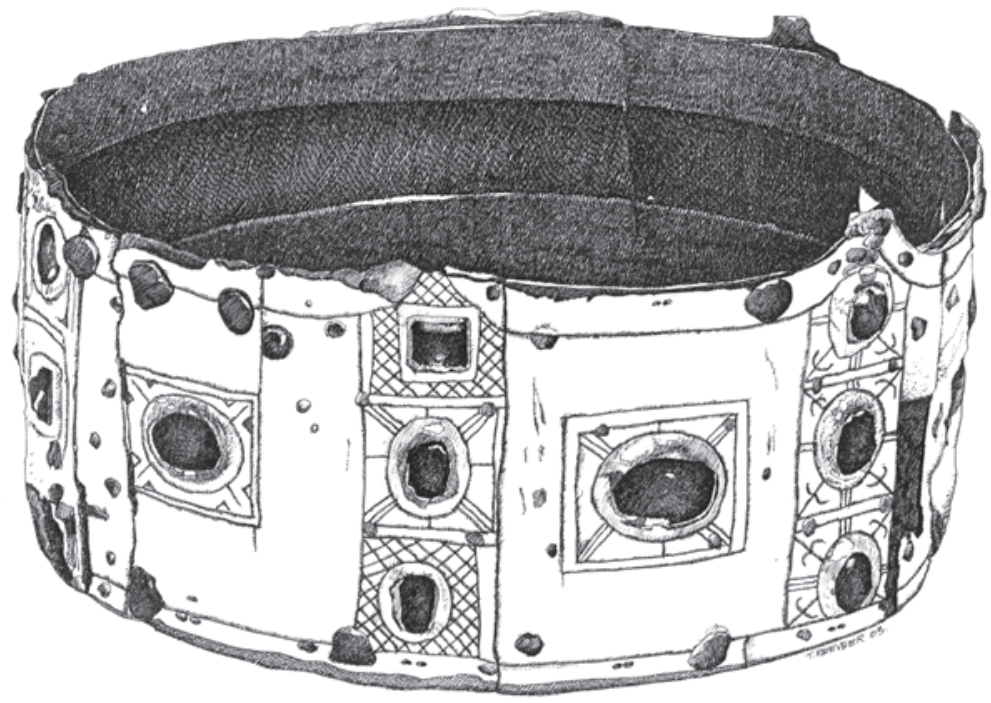

Vanim säilinud kroon Rootsis, leitud Püha Eriku reliikvialaekast. Sundqvist 2002 järgi Tõnu Reeveer.

váru Eistr (Aðalbjarnarsson 1979: 230)). Pigem on tõenäoline, et niivõrd tähtsa loo, nagu seda oli kuninga vangilangemine, kirjapanekul oli vaja teada kõigi sündmuses osalejate nimesid ja need lihtsalt "taastati", eesmärgiks taas loo usutavus ning usaldatavus. See seletaks ka nii nimede skandinaaviapärasuse kui omalaadse rühmitamise (Klerkon-Klerkr ja Réas-Rékon-Rékoni).

Läänemere idaranniku heale tundmisele ja kontaktidele viitavad ka mitmed toponüümid. Nii on Raivo Palmaru oletanud, et Saaremaa (Eysýsla) ja Lääne-Eesti (Aðalsýsla) nimed on saagadesse sattunud saarlaste vahendusel ning eesti keelest tõlgituna. Eysysla tähendab sõna-sõnalt saare maad, ka maakonda või piirkonda. Eesliide aðal-viitab aga suurele, peamisele, seega tähendab Aðalsýsla Suurt maad (ehk maismaad), mis võis olla just saarlaste nimetus Eesti mandriosale, kõige tõenäolisemalt Läänemaale (Palmaru 1980: 268).

Kahetähenduslikuna on kasutatud sõna Eestimaa (Eistland), mille all on enamasti mõeldud Eestit üldiselt (näiteks Ólafs saga Tryggvasonar 6), teinekord aga mingit kitsamat piirkonda (ÖrvarOdds saga 30). Raivo Palmaru on oletanud, et Eistland on tähendanud piirkonda Viru- ja Liivimaa vahel (Palmaru 1980: 267). Kõige 
tõenäolisem tundub aga, et Eistlandi on kasutatud märkimaks kas Eestit üldiselt või on seda kasutatud nende Eesti piirkondade kohta, mille täpsemat nime ei teatud. Maakonnanimedena on saagakirjanikele olnud ootuspäraselt tuntud just rannikuäärsed maakonnad. Nii esinevad mitmel korral Vírlandi (Virumaa) ja Rafala (Rävala) nimed (Örvar Odds saga 30, Brennu Njáls saga 30), millele lisanduvad ka Eysýsla ja Aðalsýsla. Sellest võibki arvata, et Eistland tähistas kokkuvõtlikult just Eesti sisemaad. Virland ning Rafala on saagades olnud kasutusel maakondade kohta. Vaid Noole-Oddi saaga (Örvar-Odds saga) 30. peatükis on nimetatud Rafalalandi, mis justkui rõhutaks sõna "maa" tähtsust ja võiks nii viidata ka väiksemale, samanimelisele asulale (võimalik, et hilisemale Tallinnale).

Nii üsna täpne topograafia kui ka skandinaaviapärased isikunimed näivad sellise vaatluse põhjal viitavat, nagu oleks Läänemere idarannikut võetud kui Põhjala kultuuriruumi üht osa. Skandinaavlastele on olnud tuttavad siinsete rannikuäärsete maakondade nimetused, samuti tundub loomulikuna suhtlus siinsete elanikega, mille sekka kuuluvad kauba-ja sõjaretked ning ühised turud. Ka skandinaaviapäraste nimede omistamine siinsetele elanikele (näiteks Olafi orjastajad ja tema pererahvas) viitab sellele, nagu ei oleks tehtud vahet skandinaavlastel kui omadel ja eestlastel kui võõrastel. Ometigi on saagades veel teine kihistus.

\section{Üleloomulikud olendid}

Põhjala eelkristliku maailmapildi järgi oli enamik trolle, jöötuneid ja teisi inimkonnale ohtlikke ja ebameeldivaid olevusi pärit ida poolt (Noorema Edda "Gylfaginning" XII). Ka Thor käis hiiglastega just idas taplemas (Noorema Edda "Gylfaginning"XLV).

Saagade järgi on mitmed hiiglased elanud kas Austrvegri lähistel või lausa Austrvegril. 14. sajandi romantilises Samsons saga fagras on öeldud, et põhja ja ida pool Austrvegrit elavad jöötunid (Wilson 1953). Kirjeldusi jöötuneist kohtame ka 14. sajandil islandi keelde tõlgitud saksi kuningapoja Sigurðri (Siegfriedi) seiklustest rääkivas Sigurðar saga Pögla 7. peatükis, kus Vilhjálmur ja Hálfdan purjetasid Saksimaalt Austrvegrile ning kohtasid seal rannas 12 küünra pikkust jöötunit (Driscoll 1992). Sel oli üks silm, nelja küünra pikkune sarv, suured hambad ja suur suu, ta oli ilma kaelata ja lühikeste juustega. Saaga järgi pidada jöötunid olema inimsööjad ja raamatuis kutsutavat neid 


\section{Tõnno Jonuks}

kükloopideks. Jöötunistjagu saamiseks visati tal peenikese odaga silm peast välja. Huvitava väljendina esineb siin kükloobi nimetus ja selle päritolu seletus. Fraas seda trolliliiki kutsutavat raamatuis... viitab juba iseenesest kirjandusest saadud mõjutustele, mis on aidanud loo kirjutajal sellist tegelast luua. Ühesilmalisus, kükloobi nimi ja temast jagu saamise viis näitab selgelt, et autor tundis klassikalisi kreeka müüte. Ja et põhjalased kreeklastest viletsamad ei oleks, laskis autor Vilhjálmuril ja Hálfdanil lõpuks mitte ühest, vaid kuuest sellisest koletisest vigastamatult jagu saada.

Hiiglastega seondub ka üks saagadest inspireeritud keskaegse kroonika teade. Saxo Grammaticuse 12.-13. sajandil kirja pandud Gesta Danorumi järgi on Eestist pärit üks Põhjala kuulsaim berserkr - Starkatherus/Starkaðr. Berserkrid (karuhamed) ja nende kaaslased úlfheðnarid (hundinahksed) olid jumal Odinile pühendunud sõdalased, kelles olid esindatud temale iseloomulik raev ja spontaansus ning kelle puhul sõdimine ja võitlus seostusid religiooniga (Puhvel 1996: 199). Odini meestest räägitakse ka Ynglingite saaga 6. peatükis, mille järgi nad:

[---] ei hooli turvisest ja kes on hullud nagu koerad või hundid, hammustavad oma kilpe, on tugevad nagu karud või pullid. Nad tapavad inimesi ja ei tuli ega raud ei hakka nende peale. Seda kutsutakse berserkluseks (Aðalbjarnarson 1979: 17).

Starkaðri päritolu kohta öeldakse Sögubróti 8. peatükis, et ta kasvas üles Norras. Sögubrótile tuginedes seostavad Axel Olrik ning J.R. R. Tolkien Starkaðri muistse vee- või kosevaimuga, mis aga Hilda R. Ellis Davidsoni arvates võib olla ka hilisem seos (vt lähemalt Davidson 1980 II: 99). Starkaðri põhiallikana on kasutatud peamiselt Islandil üles kirjutatud Gautreks-saagat. Saxo aga, kes tundis müüti Strakaðrist kui kaheksakäelisest hiiglasest, kellelt Thor kuus kätt maha raius ja ta sellisena inimesetaoliseks taandas, paigutab Starkaðri vastavalt paganlikule maailmapildile ja selle jäänukitele kristlikus maailmapildis itta, Jöötunite maale (Jötunheimi) ehk Eestisse (Estonae). Tõsi, ka Saxole tundus lugu juba uskumatu, nagu ta isegi on oma kroonikas maininud. James Milroy puudutab Starkaðri põlvnemist vaid põgusalt ja nendib, et selle loo puhul võib tegemist olla klassikalise müüdiga (Milroy 1976: 130). Ometigi ei seleta see, miks Saxo selle hiiglasliku võitleja päritolu nii täpselt määratles.

Erinevalt saagasid kirja pannud islandlastest oli Saxole berserkride peamiseks tunnuseks peetud ja eespool nimetatud pühen- 
dumine raevu ja spontaansuse jumalale Odinile ilmselt teisejärguline - kui selline seos üldse tekkis. Kõige tõenäolisemalt oli Saxo silmis määrav Starkaðri põlvnemine hiiglastest ja sealtkadu tema päritolu Útgarðrist kui paganlikult ja vaenulikult maalt. Seega paigutaski Saxo vastavalt endisele ettekujutusele sellise hiiglase sünnikoha itta. Vägivaldse sõdalase idapoolse päritolu kasuks võis tõenäoliselt kõnelda ka seik, et 12.-13. sajandi Baltikumist pärit meresõitjad olid Skandinaavias viikingiaja ümbersaamise järel võimu Läänemerel enesele haaranud.

Hoopis teistsugust elukat kohtas Njálli saagas islandlane Porkell hákur (vt Alas 2001, ptk 119), kes, olles Rootsi kuningas Sörkvi teenistuses, sattus Austrvegrile. Kõigepealt kohtas ta Bálagarðssýslas (koht Soome edelarannikul (Aðalbjarnarson 1974: 52)) poolmees-poollooma, kelle ta tappis, ning seejärel Aðalsýslasse jõudes lenddraakonit (flugdreka), kelle ta samuti surmas. Huvitavaks teeb selle loo veel ka asjaolu, et draakon on saagades üsna harva esinev tegelane, kelle ilmumiskohaks on tavaliselt hoopis lõunamere saared, nagu Björn saga 5. peatükis, kus draakon ründab Björni laeva. Kristel Zilmer juhib tähelepanu ka Porkelli hüüdnimele hákur, mida võib tõlkida kui 'latard, ärpleja' ning seega võiks kogu loo tembeldada meremehejutuks (Zilmer 2003).

\section{Kokkuvõtteks}

Nagu näitavad mitmed saagade kohanimed, sündmused ja kirjeldused, oli Läänemere idarannik muistsetele skandinaavlastele tuttav ja suhtlemine üle Läänemere oli üsna tihe. Sama kinnitab ka arheoloogiline esemematerjal (Kriiska \& Tvauri 2002: 247).

Sellisest realistlikust suhtlemisest eristuvad aga selgesti mõned kirjeldused hiiglastest, draakonitest jt, kelle elupaigaks on peetud Idateed või selle lähiümbrust. Ilmselt tuleb selliste motiivide tekkepõhjust otsida eeskätt veel keskajalgi püsinud Põhjala eelkristlikust maailmapildist, kus põhja- ja idakaares, s.t hiiglaste maal Útgarðris elutsesid inimestele ohtlikud ja võõrad jõud. Selline käsitlus maailmast ei ole jätnud jälgi mitte ainult ilmalikele, vaid ka islandi päritolu kristliku taustaga saagakirjanikele, kelle lisandustena tõenäoliselt ongi ilmunud muidu realistlikesse saagatekstidesse mütoloogilised olendid.

Kindlasti oli sellise nägemuse üheks tõukejõuks ka keskaegne religioonipilt Põhja-Euroopas, kus enamik alasid oli 13. sajandi al- 


\section{Tõnno Jonuks}

guseks ristitud ja kuulusid kirikukihelkondade ja piiskopkondade kaudu nn tuntud maailma, oikumeeni. Sellistest maadest eristusid aga Soome ning praeguse Eesti ja Läti alad. Kindlasti olid sealsed elanikud juba tuttavad ristiusuga (Mägi 2002: 154), teadaolevalt oli nende hulgas ristituid (nt Kleis 1982: 199), kuid kuni maa ei kuulunud kiriku institutsioonide kaudu tuntud maailma, oli tegemist võõra ja mittekristliku alaga. Sellist pilti võimendas omakorda 12. sajandi lõpul alanud ristisõda Maarjamaale ning selle ideoloogiline põhjendamine Rooma paavsti poolt.

Tõenäoliselt selliste vaadete tulemusena ongi islandi saagakirjanikud loonud kristliku oikumeeni kõrvale paganliku koha, kuhu oli kerge sobitada nii hiiglasi kui ka draakoneid, kes sümboliseerisid inimestele vaenulikke jõude eelkristlikus Põhjalas ja samuti kristlikus Euroopas. Ehkki Idatee oli Skandinaavia meresõitjatele juba sajandeid teada ja tuntud, muutus termin valitseva maailmapildi mõjul ähmasemaks ja taas sobivamaks ebainimlikele jõududele. Koos Idateega tabas sama saatus ka Lääneteed, Vestrvegrit ja sellegi kaugemaid piirkondi, kus saagade järgi elasid samuti hiiglased jt.

Siinesitatud kolmest näitest hiiulugude kohta kuuluvad kaks nn rüütlisaagade hulka. Rüütlisaagad kui žanr on saagakirjanduses hiline nähtus, pärit enamasti alates 14. sajandist. Rüütlisaagade hulka kuuluvad keskaegsed rüütlilood, mis on tõlgitud islandi keelde ja mõnevõrra muudetud kujul saanud saagapärase värvingu. Rüütlisaagadesse, mille sisul ei ole Põhjala kultuuriruumiga otsest seost, oli kõige kergem sisse pikkida hilisemaid lisandusi, millest mõne puhul on viidatud, et tegemist on raamatust võetud laenuga (nagu näiteks Sigurðar saga Pögla).

Omaette küsimus on sellise maailmavaate levik. Sõltume ju selle probleemi vaatlemisel eelkõige kristlikest saagakirjanikest endist. Igal juhul tundub väheusutav, nagu oleks selline kujutlus olnud keskaegses Põhja-Euroopas valdav. Ilmalikes rahvausundeis segunesid vanemad, paganlikud kujutlused kristlikega ikka nii nagu mujalgi. Konflikt paganlike kujutluste ning kristliku arusaamisega tekkis aga vaimulikel, kellele sellistes küsimustes selguse saamine oli hoopis tähtsam. Samuti olid nemad need, kes kirjakunsti valdasid ja saagad kirja panid.

Seega saab saagatekstides eristada Eesti kohta kaht kihistust: esimene ja laiemalt levinu moodustab saagade põhiosa ning viitab realistlikele ja tihedatele suhetele ühtses Põhjala kultuuriruumis, teine kui saagakirjanike loodud kihistus kujutab Eestit ja Lääne- 
Tõnno Jonuks

mere idarannikut üldiselt kui üht viimast mittekristlikku erilist ja kummalist maad Euroopas.

\section{Kirjandus}

Aðalbjarnarson, Bjarni 1979. Snorri Sturluson. Heimskringla I. Íslenzk fornrit 26. Reykjavík: Hið íslenzka fornritafélag.

Alas, Arvo (tõlk) 1982. Grettir Ásmundripoja saaga. Loomingu Raamatukogu 33-35. Tallinn: Perioodika.

Alas, Arvo (tõlk) 2001. Njálli saaga. Tallinn: Varrak.

Alas, Arvo (tõlk) 2003. Viikingid Vinlandis: Eiríks Punase saaga. Gröönlaste saaga. Loomingu Raamatukogu 7-8. Tallinn: Perioodika.

Alas, Arvo 1999. Islandi saagad ja Eesti. Looming 2. Tallinn, lk 244-248.

Davidson, Hilda Roderick Ellis 1980. The History of the Danes / Saxo Grammaticus. Books I-IX. Vol I-II. London: D. S. Brewer, Rowman \& Littlefield.

Driscoll, Matthew James (toim) 1992. Sigurðar saga Pögla: The shorter redaction. Reykjavík: Mál og menning.

Eldjárn, Kristján 1956. Kuml og haugfé i heiðnum sið á Íslandi. Reykjavík.

Gurevitš, Aron 1975. Viikingite retked. Jüri Selirand (tõlk). Tallinn: Valgus.

Johansen, Paul 1974. Saxo Grammaticus und das Ostbaltikum. Zeitschrift für Ostforschung Länder und Völker im östlichen Mitteleuropa 23: 4. Marburg: Verlag J. G. Herder-Institut, lk 623-639.

Jonuks, Tõnno 2000. Usund Eestis nooremal rauaajal kirjalike ja arheoloogiliste allikate näitel. Peaseminaritöö. Käsikiri Tartu Ülikooli arheoloogia õppetoolis. Tartu: Tartu Ülikool.

Kann, Aleksander 1919. Asgard: Skandinaawlaste muinaslood. Tallinn: J. ja A. Paalmann.

Kleis, Richard (tõlk) 1982. Henriku Liivimaa Kroonika. Tallinn: Eesti Raamat.

Kriiska, Aivar \& Tvauri, Andres 2002. Eesti muinasaeg. Tallinn: Avita.

Kruse, Friedrich 1846. Ur-geschichte des Estnischen Volkstammes und der Kaiserlich Russischen Ostseeprovinzen Liv-, Esth- und Kurland überhaupt, bis zur Einführung der christlichen Religion. Moskva: Severin.

Nerman, Birger 1929. Die Verbindung zwischen Skandinavien und das Ostbaltikum in der jüngeren Eisenzeit. Kungl. Ant. Akad. Handlungen 40: 1. Stockholm: $\mathrm{Pa}$ Akademiens forlag. 


\section{Tõnno Jonuks}

Page, Raymond Ian 1964. Lapland sorcerers. Saga-Book XVI: 2-3 (19631964). London: University College London, lk 215-232.

Palmaru, Raivo 1980. Eesti vanimais kirjalikes allikates. Keel ja Kirjandus 5, lk 261-269.

Price, Neil S. 2002. The Viking Way: Religion and War in Late Iron Age Scandinavia. Aun 31. Uppsala: Department of Archaeology and Ancient History.

Puhvel Jaan 1996. Võrdlev mütoloogia. Tartu: Ilmamaa.

Saluäär, Anu 2000. Saxo Grammaticus: Taanlaste vägiteod. Loomingu Raamatukogu 8-10. Tallinn: Perioodika.

Sepp, Rein (tõlk) 1970. Vanem Edda. Tallinn: Eesti Raamat.

Sepp, Rein (tõlk) 1990. Noorem Edda. Valik tekste: Tallinn: Eesti Raamat.

Shetelig, Haakon \& Falk, Hjalmar 1937. Scandinavian Archaeology. Oxford: Oxford University Press.

Smissen, Johannes van der 1849. Olaf der Heilige auf Oesel, nebst einigen Bemerkungen über die Nachrichten der Isländer von Estland. Friedrich Georg von Bunge (väljaaandja \& toim). Das Inland: Eine Wochenschrift für Liv-, Esth- und Curländische Geschichte, Geographie, Statistik und Litteratur 35. Dorpat: C. A. Kluge, lk 600-604.

Steblin-Kamenski, Mihhail 1974. Islandi kultuur. Arvo Alas (tõlk). Tallinn: Eesti Raamat.

Sundqvist, Olof 2002. Freyr's offspring: Rulers and religion in ancient Svea society. Historia Religionum 21. Acta Universitatis Upsaliensis. Uppsala: Uppsala universitetet.

Sveinsson, Einar Ólafur 1954. Brennu Njáls saga. Íslenzk fornrit 12. Reykjavík: Hið íslenzka fornritafélag.

Zilmer, Kristel. Kommunikatsioonist ja kontaktidest Läänemere piirkonnas islandlaste saagade andmetel. Mare Kõiva (koost, toim). Sator 3: Artikleid usundi- ja kombeloost. Tartu 2003, lk 27-47.

Tegnér, Esaias 1922. Frithjof: Skandinaavia Kalevipoeg. Peeter Grünfeldt (tõlk). Tallinn: Tallinna Eesti Kirjastus-Ühisus.

Wilson, John (toim) 1953. Samsons saga fagra. Samfund til udgivelse af gammel nordisk litteratur 65: 1. København: J. Jørgensen. 